\title{
Investigation of Gender Differences Related to Knee Strength Asymmetry
}

\section{Diz Eklem Kuvveti Asimetrisinde Cinsiyetler Arası Farklılıkların Incelenmesi}

\author{
Celil Kaçoğlu \\ Department of Coaching Education, Faculty of Sport Sciences, Eskişehir Technical University, Eskişehir, Turkey
}

\section{Kaçoğlu 0000-0002-1817-5234}

Geliş Tarihi/Date Received: 04.12.2018

Kabul Tarihi/Date Accepted: 29.01.2019

Yayın Tarihi/Published Online: 09.05.2019

Yazışma Adresi /

Corresponding Author:

Celil Kaçoğlu

Eskişehir Teknik Üniversitesi, Spor Bilimleri Fakültesi, Antrenörlük Eğitimi Bölümü, Eskişehir, Turkey

E-mail:

ckacoglu@anadolu.edu.tr

(C2019 Türkiye Spor Hekimleri Derneği. Tüm hakları saklıdır.

\begin{abstract}
Objectives: Inter-limb strength asymmetry is one of the major risk factors for noncontact injuries in sport. The determination of strength asymmetry provides an important information to develop different strategies for injury prevention and risk management in sport. It is not well-known whether inter-limb strength asymmetry differences exist between genders. The aim of this study was to determine the contralateral knee strength asymmetry differences between genders.

Material and Methods: Thirty-three physically active but not highly-trained individuals (Age: $21.4 \pm 2.9$ years, height: $1.75 \pm 0.07 \mathrm{~m}$, body weight: $66.2 \pm 9.6 \mathrm{~kg}$, body fat ratio: $15.2 \pm 5.7 \%$, BMI: $21.6 \pm 2.3 \mathrm{~kg} / \mathrm{m}^{2}$ ) voluntarily participated in this study. Approximately one week after the familiarization phase, all subjects performed knee isokinetic strength tests at slow $\left(60^{\circ} . \mathrm{s}^{-1}\right)$, medium $\left(180^{\circ} . \mathrm{s}^{-1}\right)$ and fast $\left(300^{\circ} . \mathrm{s}^{-1}\right)$ angular velocities for right and left knee flexion-extension movement. The symmetry angle formula was used to calculate the contralateral strength asymmetry scores between lower-limbs. The differences between symmetry angles and genders were analyzed using independent sample t-test.

Results: It was found that flexion and extension isokinetic contralateral knee strength asymmetry scores at slow, medium and fast angular angular velocities did not reveal any statistically significant differences between genders $(p>0.05)$.

Conclusions: It has been found that there were no differences between concentric isokinetic knee strength symmetry angle scores between genders at all angular velocities in physically active but not highly-trained individuals.

Keywords: Isokinetic strength, strength balance, symmetry angle, gender
\end{abstract}

\section{ÖZ}

Amaç: Ekstremiteler arası kuvvet asimetrisi temassız spor yaralanmaları açısından önemli bir risk faktörüdür. Kuvvet asimetrisinin belirlenmesi, spor yaralanmalarından korunma ve risk yönetimi konusunda spor sağlık bilimcilerine farklı stratejiler geliştirebilmeleri için bilgi sunmaktadır. Fakat kuvvet asimetrisi yönünden cinsiyetler arası farklılıklar net olarak bilinmemektedir. Bu çalışmanın amacı, kontralateral diz eklem kuvvet asimetrisini ve cinsiyetler arası farklılıkları belirlemektir.

Gereç ve Yöntemler: Bu çalışmaya 33 birey (Yaş: $21.4 \pm 2.9$ yıl, boy: $1.75 \pm 0.07 \mathrm{~m}$, vücut ağırlığı: $66.2 \pm 9.6 \mathrm{~kg}$, vücut yağ oranı: \%15.2 \pm 5.7 , beden kitle indeksi $(B K i)$ : $21.6 \pm 2.3 \mathrm{~kg} / \mathrm{m}^{2}$ ) gönüllü olarak katıldı. Tüm katılımcılar deneme ve tanıtım seansından yaklaşık bir hafta sonra, düşük $\left(60^{\circ} . \mathrm{s}^{-1}\right)$, orta $\left(180^{\circ} . \mathrm{s}^{-1}\right)$ ve yüksek $\left(300^{\circ} . \mathrm{s}^{-1}\right)$ açısal hızlarda sağ ve sol izokinetik konsantrik diz fleksiyon ve ekstansiyon kuvvet testlerine katıldılar. Alt ekstremiteler arası kontralateral kuvvet asimetrisi değerlerini belirlemek 
için simetri açı formülünden yararlanıldı. Simetri açı değerleriyle cinsiyetler arasında fark bağımsız örneklem T-testi ile incelendi.

Bulgular: Analizler sonucunda; düşük, orta ve yüksek açısal hızlardaki kontralateral fleksiyon ve ekstansiyon izokinetik diz kuvvet asimetrisi değerlerinin, kadın ve erkek grupları arasında istatistiksel olarak anlamlı bir farklılık göstermediği ortaya kondu ( $p>0.05)$.

Sonuç: Elde edilen bulgular doğrultusunda; fiziksel olarak aktif ancak üst düzeyde antrenmanlı olmayan bireylerde düşük, orta ve yüksek açısal hızlardaki kontralateral izokinetik diz kuvvetleri simetri açı değerlerinin kadın ve erkeklerde benzer olduğu sonucuna ulaşıldı.

Anahtar Sözcükler: İokinetik kuvvet, kuvvet dengesi, simetri açısı, cinsiyet

Available at: http://journalofsportsmedicine.org and http://dx.doi.org/10.5152/tjsm.2019.136

Cite this article as: Kacoglu C. Investigation of gender differences related to knee strength asymmetry. Turk J Sports Med. 2019;54(4):225-32.

\section{Gíriş}

Kuvvet asimetrisi, genellikle her iki bacak maksimal kuvvet değerlerinin bir referans noktasına göre kontralateral (sağ ve sol taraf hamstring/hamstring ya da quadriceps / quadriceps gibi) veya ipsilateral (sağ ya da sol taraf hamstring / quadriceps gibi) oranlarını ifade etmektedir (1,2,3). Kas kuvvet asimetrisinin, fiziksel temas nedenli olmayan spor yaralanmalarının en önde gelen üçüncü risk faktörü olduğu spor bilimcileri, fizyoterapistler ve tıp doktorları tarafından kabul görmektedir $(4,5)$. Ekstremiteler arası kuvvet asimetri değerleri, yaralanmaların önlenmesi ve yaralanmalardan korunma açısından sıklıkla göz önünde bulundurulmaktadır.

Kas kuvvet asimetrisinin \%10-15'ten fazla olmasının yaralanma riskini arttırdığ 1 (6,7), hamstring/quadriceps (H/Q) kuvvet oranının $\% 60$ 'dan daha düşük olmasının ise alt ektremite yaralanmalarıyla ilişkili olduğu belirtilmektedir (8). Ekstremiteler arasi kuvvet asimetri oranlarının belirlenmesi ve olası kuvvet farklılıklarının konvansiyonel, fonksiyonel veya izokinetik antrenman programlarıyla azaltılması ya da güvenli aralıklarda tutulması, spor yaralanmalarından korunma yönünden oldukça önemlidir (9). Sportif performans düşüşleriyle ilişkili olan kas kuvvet dengesizliklerinin erken dönemde izokinetik uygulamalarla saptanması kas yaralanmalarını önleyebilme açısından önemlidir $(7,10)$. Bunun yanı sıra, postüral bozukluk (11) ve patellofemoral ağrı (12) gibi durumlarda ekstremiteler arası kuvvet dengesizliklerini gidermeye yönelik egzersiz reçeteleri önemli tedavi yöntemleri olarak önerilmektedir. Öte yandan, alt ekstremitelerde hem agonist-antagonist kaslar hem de kontralateral homolog kaslar arasındaki kuvvet oranını korumak, gerek spor yaralanmalarından korunmada, gerekse de atletik performansta oluşabilecek kayıpların giderilmesinde önemli bir yere sahiptir (13-15).

Asimetri değerlendirmelerinde, dominant ya da daha güçlü olan tarafın referans noktası alınarak yüzde şeklinde sonuç veren çeşitli hesaplamalar kullanılmaktadır (16). Örneğin, güçlü tarafı referans noktası alan bir hesaplama sonucunda "sol quapriceps kuvveti, sağ quariceps'e göre \%10 daha düşük" șeklindeki bir ifade, antrenör veya spor uzmanlarına asimetri oranını basit şekilde değerlendirme olanağı sunmaktadır. Literatürde kuvvet farklılıklarını belirlemede sağ/sol taraf oranı, asimetri indeksi, simetri açısı gibi asimetri veya simetri odaklı farklı formüller kullanılmaktadır $(1-3,16)$. Bunun yanı sira simetri ve asimetri terimleri benzer anlamda kullanılabilmektedir. Kavramsal olarak simetri, bir tarafın hareketini diğer tarafın da aynı şekilde yansıtabilmesi olarak tanımlanırken, asimetri simetriden sapmayı ifade etmektedir (17).

Diz fleksiyon ve ekstansiyon kuvveti hem zirve tork değeri olarak hem de vücut ağırlığına göre oransal olarak kadınlarda erkeklere göre daha düşüktür (18). Bu farklılığın hem yağsız vücut 
kütlesi hem de deri altı yağ oranından kaynaklanabileceği belirtilmiştir (19). Buna ek olarak diz kuvveti; anatomiden, hormonal durumdan, diz eklemi çevresindeki ligamentlerin laksitesinden ve menstural döngü gibi cinsiyetle ilgili faktörlerden etkilenebilmektedir (20). Ayrica kadın ve erkekler arasında koşu kinematikleri arasında da farklılıklar bulunmaktadır (21). Tüm bu farklılıkların belirtilmiş olmasına karşın diz kuvvet asimetrisinin cinsiyet faktöründen etkilenip etkilenmediğine ilişkin bir araştırmaya ulaşılamamıștır.

Kuvvet asimetri değerlerindeki artışın yaralanma riskiyle ilişki olduğu (5), sporcunun performansını sinırlayabileceği (22) veya performansa negatif etki edebileceği (23) belirtilmiştir. Bu sonuçlar doğrultusunda spor sağlık bilimcilerinin ve antrenörlerin ekstremiteler arası olası kuvvet dengesizliklerini azaltma, fonksiyonel performansı arttırma veya spor yaralanmalarından korunma amaçlı hazırlayacakları programlarda cinsiyetler arası farkı gözetme konusunda zorluklar yaşayabilecekleri düşünülmektedir. Böyle bir bilgi, asimetriyle ilgili olarak planlanan antrenmanlardan daha net sonuçların elde edilmesini sağlayabilecektir.

Antrenmansız ve fiziksel olarak düşük düzeyde aktif yetişkin kadın ve erkeklerde $\mathrm{H} / \mathrm{Q}$ patlayıcı kuvvet oranları birbirine yakın değerlerde görülürken (24), 8-12 yaş arası kızlarda H/Q oranı erkeklere göre $\% 10$ daha düșüktür (25). Bununla birlikte $11-20$ ve $41-60$ arası yaş gruplarında $\mathrm{H} / \mathrm{Q}$ kas kuvvet oranı açısından cinsiyetler arasında farklılık gözlenmezken, 2140 yaş grubunda erkeklerde kadınlara göre daha yüksek H/Q oranı görülmektedir (26). Ayrıca H/Q kuvvet oranı düşük açısal hızlarda kadın ve erkeklerde farklılık göstermemesine karşın, yüksek açısal hızlarda kadınların erkeklere göre $\mathrm{H} / \mathrm{Q}$ oranı açısından yetersiz kaldıkları belirtilmiştir (27). Ayrıca baskın ve baskın olmayan taraf el kavrama kuvvet oranlarının kadınlarda daha fazla olduğu görülmüștür (28).
Çalışmalar yaş ve hareket hızına göre cinsiyetler arasinda kas kuvvet dengesizlikleri bulunabileceğini göstermektedir. $\mathrm{Bu}$ açıdan bakıldığında, kontralateral kuvvet asimetri değerlerinde de cinsiyetler arası farklılık olabileceği akla gelmektedir. Buradan hareketle bu araştırmanın amacı ekstremiteler arası kontralateral diz kuvvet simetri açı değerlerinde cinsiyetler arasında fark olup olmadığının belirlenmesidir. Araştırmanın hipotezi; "düşük, orta ve yüksek açısal hızlardaki kontralateral izokinetik diz kuvvet asimetri değerlerinde kadın ve erkekler arasında farklılık vardır" şeklinde kurulmuştur.

\section{GEREÇ ve YÖNTEMLER}

$\mathrm{Bu}$ çalışmada izokinetik diz kuvvet simetri açılarında cinsiyetler arası farklılık araştırıldı. İzokinetik diz kuvvetini belirlemede düşük $\left(60^{\circ} . \mathrm{s}^{-1}\right)$, orta $\left(180^{\circ} . \mathrm{s}^{-1}\right)$ ve yüksek $\left(300^{\circ} . \mathrm{s}^{-1}\right)$ açısal hızlarda konsantrik fleksiyon ve ekstansiyon zirve tork değerleri kullanıldı.

Çalışmaya fiziksel olarak aktif fakat üst düzeyde antrenmanlı olmayan, yaşları $21.4 \pm 2.9$ yıl (ortalama \pm standart sapma), boy uzunlukları $1.75 \pm 0.07 \mathrm{~m}$, vücut ağırlıkları $66.2 \pm 9.6 \mathrm{~kg}$, vücut yağ oranları $15.2 \pm 5.7 \%$ ve beden kitle indeksleri (BKI) $21.6 \pm 2.3 \mathrm{~kg} / \mathrm{m}^{2}$ olan 20 erkek, 13 kadın olmak üzere sağ tarafları baskın toplam 33 birey gönüllü olarak katıldı. Kesitsel bir araștırma olan bu çalışmada katılımcıların tamamı aynı ölçümlere alındı. Katılımcılarda, haftada en az iki gün olmak üzere düzenli olarak orta şiddetli fiziksel aktivitelere katılıyor olma şartı arandı. Katılımcılar belirlenirken alt ekstremite spor yaralanmalarının bulunmaması ve daha önce alt ekstremite yaralanması geçirmemiş olmaları göz önünde bulunduruldu.

Bütün katılımcılara çalışma öncesinde bilgilendirme yapıldı, çalışmaya gönüllülük esasına göre katılım yapacakları ve çalışmanın herhangi bir bölümünde çalışmadan ayrılma konusunda özgür oldukları belirtilerek imzalı onayları alındı. Bu çalışma için Eskişehir Osmangazi Üniversitesi Girişimsel Olmayan Etik Kurulundan etik kurul onayı alındı. Çalışma boyunca Helsinki Deklarasyonuna uygun şekilde hareket edildi. 


\section{Araştırmanın Tasarımı}

Tüm katılımcılara, ölçümlerden yaklaşık bir hafta önce testlerin tanıtımı ve birebir denemesi yaptırılarak adaptasyonları sağlandı. Bu deneme ve tanıtım gününde katılımcıların tanımlayıcı istatistiklerinden olan boy uzunlukları sabit duvar stadiometresiyle (Holtain Ltd., İngiltere), vücut ağırlıkları ve vücut yağ oranı ölçümleri ise bir biyoelektrik empedans analizörüyle (Tanita MC 180MA, Japonya) yapıldı. Bundan yaklaşık bir hafta sonra ise asıl testler uygulandı. Katılımcılara ölçümlerden önceki gün şiddetli fiziksel aktivitelere katılmamaları, rutin beslenme ve hidrasyonalarına devam etmeleri, kafein ve alkol tüketmemeleri ve yeterli süre uyumaları konusunda sözlü bildirimler yapıldı. Her ölçümden önce testin içeriği katılımcılara sözlü olarak tekrar aktarıldı.

\section{Ölçüm ve Analizler}

İzokinetik Kuvvet Testi: İzokinetik diz kuvvet testleri bir izokinetik dinamometre (Humac Norm Testing \& Rehabilitation System, Model TM 770, ABD) kullanılarak yapıldı. Ölçüm günlerinde testler öncesi cihaz kalibre edildi.

Ölçümlerin öncesinde katılımcılar yüksüz bisiklet çevirme içeren yaklaşık 10 dakikalık standart bir ısinma uyguladılar. Isınma sonrası 5-6 dakika dinamik germeler ve submaksimal dinamik kontraksiyonlar içeren kalistenikler ve pliometrik sıçramalar uygulandıktan sonra 3-5 dakika pasif dinlenme arası verildi ve ardından ölçümlere geçildi. Dinlenme sonrası test edilecek katılımcının fiziksel özelliklerine göre cihazın koltuk ve dinamometre açı ayarlaması yapıldı, baldır ve gövde kayışları rahatsızlık oluşturmayacak şekilde sıkılarak katılımcının koltuğa sabitlenmesi sağlandı. Test prosedürü katılımcılara açıklandı ve testler sırasında sözlü motivasyon yapildı.

Dinamometrenin ayarlanabilir kolunda bulunan yumuşak ped, katılımcının ayak bileğinin dorsal fleksiyonuna izin verecek şekilde medial malleolün proksimal hizasından bacağa sabitlendi. Dinamometre kolunun aksis rotasyonu lateral femoral kondil hizasina ayarlandı. Her açısal hız öncesi ısınma ve alışma amaçlı üç submaksimal tekrar yapıldı, sonrasinda 30 saniye pasif dinlenme verildi. Pasif dinlenme sonrası araları 1 dakikalık dinlenmeler içeren düşük $\left(60^{\circ} . \mathrm{s}^{-1}\right)$, orta $\left(180^{\circ} . \mathrm{s}^{-}\right.$ $\left.{ }^{1}\right)$ ve yüksek $\left(300^{\circ} . \mathrm{s}^{-1}\right)$ açısal hızlarda izokinetik testler uygulandı. Her açısal hızda beş konsantrik maksimal fleksiyon-ekstansiyon hareketi yapıldı. Sağ ve sol diz ölçümleri arası koltuk ve dinamometre ayarlaması için yaklaşık 2-3 dakika ara verildi; sonrasında diğer ekstremite ölçümü yapılarak testler tamamlandı. Testler sağ ve sol ekstremitede uygulandı ve test sonucunda cihaza bağlı bir bilgisayar aracığıyla zirve tork değerleri $(\mathrm{Nm})$ değerlendirme için kaydedildi $(29,30)$.

Asimetri Analizi: En basit şekliyle bir asimetri hesaplaması, baskın veya daha kuvvetli olan taraf referans değeri alınarak yüzde olarak hesaplanabilir (Eşitlik 1). Bununla birlikte ekstremiteler arası asimetri hesaplamasında çok farklı asimetri formülleri $(1-3,16)$ kullanılmakta, bu hesaplamaların sonuçları birbirinden farklılık gösterebilmektedir (3). Bu farklı hesaplamalar arasında simetri açısı formülü, sağ ve sol tarafın değerlerini bir vektör olarak kullanarak asimetrinin yönünü ortaya koyabilmektedir (2). Bunun yanı sira standart bir referans noktası kullandığı ve elde edilen verinin yapay olarak şişme olasılığını azalttığı için asimetri değerlerinin belirlenmesi için Zifchock ve ark.'nın (2) simetri açı formülünden yararlanıldı (Eşitlik 2). Bu formülde simetri açı değeri $\% 0$ ise mükemmel simetri olduğu anlamına gelmektedir (3). Sonucun negatif olması sol taraf değerinin, pozitif olması ise sağ taraf değerinin daha büyük olduğunu göstermektedir (2).

Eşitlik 1. Asym (\%) $=\frac{\text { maks-min }}{\text { maks }} * 100$

Eşitlik 2. $\theta_{\text {sym }}=\frac{\left(45^{0}-\arctan \left(\frac{X s o l}{X s a \breve{\mathrm{g}}}\right)\right)}{90^{0}} * 100$

Ө_sym:simetri açısı, Xsol: sol taraf izokinetik kuvvet değeri, Xsağ: sağ taraf izokinetik kuvvet değeri 


\section{İstatistiksel Analiz}

Ulaşılabilen örneklem büyüklüğü için elde edilen güç (Post-hoc power analysis) bir güç analiz yazılımı (Gpower 3.1.9.2, Brunsbuttel, Almanya) aracılığıyla hesaplandı (31-33). Posthoc güç analiz sonuçlarına göre etki büyüklügü için 0.5 (orta); örneklem büyüklüğü 1 . grup için 20, 2. grup içinse 13 seçildiğinde bu örneklem için elde edilen gücün (1- $\beta$ ), 0.40 (orta) olduğu gözlendi. Tanımlayıcı istatistikler ortalama, standart sapma olarak verildi. Ekstremiteler arası kontralateral izokinetik kuvvet simetri açı değerlerinin, kadın ve erkek grup ortalamaları arasındaki farkını belirlemek için bağımsız örneklem T-testi kullanıldı. Simetri açı değerlerinin her iki grup için de normal dağılım gösterdiği Shapiro-Wilk testiyle ( $>00.05)$, varyansların homojen dağıldığı ise Levene testiyle $(p>0.05)$ belirlendi. Her iki grupta uç değer olmadığ kondu. İstatistiksel anlamlılık değeri $\mathrm{p}<0.05$ olarak kabul edildi. Tüm analizler, SPSS (v20.0) istatistik paket programı aracılığıla değerlendirildi.

\section{BULGULAR}

Fleksiyon ve ekstansiyon diz izokinetik kuvveti ve ekstremiteler arası kuvvet simetri açı değerlerine ilişkin bilgiler Tablo 1'de gösterildi.

Tablo 1. Kadın ve erkek gruplarının izokinetik kuvvet ve simetri açı ortalama ve standart sapma değerleri

\begin{tabular}{|c|c|c|c|c|c|c|c|}
\hline \multirow{2}{*}{\multicolumn{2}{|c|}{$\begin{array}{l}\text { İzokinetik kuvvet } \\
\text { parametreleri }\end{array}$}} & \multicolumn{2}{|c|}{$60^{\circ} . s^{-1}$ acısal hız } & \multicolumn{2}{|c|}{$180^{\circ} . \mathrm{s}^{-1}$ açısal hız } & \multicolumn{2}{|c|}{$300^{\circ} . \mathrm{s}^{-1}$ açısal hız } \\
\hline & & $\begin{array}{l}\text { Tork değeri } \\
\text { (Nm) }\end{array}$ & $\begin{array}{l}\text { Simetri açısı } \\
\left(\theta_{\text {sym }}\right)\end{array}$ & $\begin{array}{l}\text { Tork değeri } \\
(\mathrm{Nm})\end{array}$ & $\begin{array}{l}\text { Simetri açısı } \\
\left(\theta_{\text {sym }}\right)\end{array}$ & $\begin{array}{l}\text { Tork değeri } \\
\text { (Nm) }\end{array}$ & $\begin{array}{c}\text { Simetri açısı } \\
\left(\theta_{\text {sym }}\right)\end{array}$ \\
\hline \multicolumn{8}{|l|}{ Erkekler } \\
\hline \multirow{2}{*}{$\begin{array}{l}\text { Ekstansiyon } \\
\text { (kuadriseps) }\end{array}$} & Sağ & $199.0 \pm 36.7$ & \multirow[t]{2}{*}{$1.3 \pm 2.7$} & $141.3 \pm 21.3$ & \multirow[t]{2}{*}{$1.7 \pm 2.5$} & $107.0 \pm 17.8$ & \multirow[t]{2}{*}{$1.0 \pm 2.6$} \\
\hline & Sol & $192.3 \pm 33.2$ & & $110.5 \pm 30.6$ & & $104.3 \pm 14.7$ & \\
\hline \multirow{2}{*}{$\begin{array}{l}\text { Fleksiyon } \\
\text { (hamstring) }\end{array}$} & Sağ & $146.6 \pm 28.9$ & \multirow[t]{2}{*}{$1.6 \pm 3.7$} & $134.5 \pm 20.2$ & \multirow[t]{2}{*}{$1.1 \pm 3.1$} & $95.3 \pm 15.0$ & \multirow[t]{2}{*}{$-0.5 \pm 3.3$} \\
\hline & Sol & $139.5 \pm 25.6$ & & $110.7 \pm 14.5$ & & $95.8 \pm 11.0$ & \\
\hline \multicolumn{8}{|l|}{ Kadınlar } \\
\hline Ekstansiyon & Sağ & $129.1 \pm 20.7$ & \multirow[t]{2}{*}{$0.2 \pm 3.8$} & $90.0 \pm 14.8$ & \multirow[t]{2}{*}{$1.3 \pm 1.8$} & $67.1 \pm 11.0$ & \multirow[t]{2}{*}{$1.4 \pm 1.9$} \\
\hline (kuadriseps) & Sol & $128.8 \pm 18.7$ & & $74.5 \pm 10.9$ & & $64.4 \pm 09.5$ & \\
\hline \multirow{2}{*}{$\begin{array}{l}\text { Fleksiyon } \\
\text { (hamstring) }\end{array}$} & Sağ & $94.5 \pm 16.0$ & \multirow[t]{2}{*}{$1.0 \pm 3.5$} & $87.0 \pm 10.0$ & \multirow[t]{2}{*}{$1.2 \pm 2.8$} & $62.9 \pm 13.3$ & \multirow[t]{2}{*}{$0.5 \pm 1.3$} \\
\hline & Sol & $91.5 \pm 15.6$ & & $72.8 \pm 12.1$ & & $62.5 \pm 12.3$ & \\
\hline
\end{tabular}

Veriler ortalama \pm standart sapma olarak verilmiştir.

Tablo 2 incelendiğinde düşük, orta ve yüksek açısal hızlarda ekstremiteler arası kontralateral fleksiyon ve ekstansiyon diz kuvvet simetri açı değerlerinde cinsiyetler arası istatistiksel olarak anlamlı fark olmadığı görülmektedir ( $p>0.05)$.

Tablo 2. Kontralateral izokinetik diz kuvvet simetri açı değerleri için cinsiyetler arası farklılık

\begin{tabular}{|c|c|c|c|c|c|c|}
\hline \multirow[t]{2}{*}{$\begin{array}{l}\text { Izokinetik kuvvet } \\
\text { parametreleri }\end{array}$} & \multicolumn{2}{|c|}{$\begin{array}{c}60^{\circ} . s^{-1} \\
\text { açısal hiz }\end{array}$} & \multicolumn{2}{|c|}{$\begin{array}{c}180^{\circ} . \mathrm{s}^{-1} \\
\text { açısal hiz }\end{array}$} & \multicolumn{2}{|c|}{$\begin{array}{c}300^{\circ} . \mathrm{s}^{-1} \\
\text { açısal hiz }\end{array}$} \\
\hline & $\mathrm{t}$ & $\mathrm{p}$ & $\mathrm{t}$ & p & $\mathrm{t}$ & $\mathrm{p}$ \\
\hline $\begin{array}{l}\text { Ekstansiyon } \\
\text { (kuadriseps) }\end{array}$ & 1.16 & 0.255 & -0.55 & 0.587 & -0.48 & 0.637 \\
\hline $\begin{array}{l}\text { Fleksiyon } \\
\text { (hamstring) }\end{array}$ & 0.42 & 0.678 & -0.10 & 0.921 & -1.19 & 0.244 \\
\hline
\end{tabular}




\section{TARTIŞMA ve SONUÇ}

$\mathrm{Bu}$ araştırmanın amacı, fiziksel olarak aktif fakat üst düzeyde antrenmanlı olmayan bireylerde düşük, orta ve yüksek açısal hızlarda ekstremiteler arası kontralateral izokinetik diz kuvvet asimetrisinin ve cinsiyetler arasındaki farklılığın incelenmesiydi. Bu araştırmanın ana bulgusu ekstremiteler arası kontralateral diz kuvvet asimetrisinin tüm açısal hızlarda cinsiyete göre farklılık göstermediği oldu.

Ön çapraz bağ rekonstrüksiyonunu izleyen bir yıl sonrası diz ekstansör kası kuvvet gelişiminin, kadınlarda erkeklere göre daha az olduğu gözlemlenmiștir (8). $\mathrm{Bu}$ gibi durumlarda planlanacak olan egzersiz reçetelerinin cinsiyetler göz önüne alınarak hazırlanması daha uygun gibi görünmektedir. Bu çalıșmanın sonuçları ise yaralanma ve rehabilitasyon süreçleri haricinde planlanan programların cinsiyetlere göre farklılı göstermesine gerek olmadığını göstermektedir.

Prepubertal kız ve erkeklerde (10-12 yaş) dikey sıçrama testleriyle belirlenen kuvvet defisiti bulunmadığı belirtilmiştir (34). Yetişkin kadın ve erkeklerde maksimal ve submaksimal izometrik diz ekstansiyon kuvvet defisitleri bulunmakla birlikte, bu defisitler cinsiyetler arası benzerlik göstermektedir (9). $\mathrm{Bu}$ sonuçlarla karşılaştırıldığında, bu araştırmada da kontralateral izokinetik diz kuvvet asimetrisinin cinsiyetler arasinda benzerlik gösterdiği görülmüştür. Ancak buna rağmen ekstremiteler arası kontralateral kuvvet asimetrilerinin cinsiyetlere göre farkının incelendiği çalışma sayısının yetersiz oluşu karşılaştırma yapılmasını güçleştirmektedir.

Maly ve ark. (35) antrenmansız genç erkeklerde (13 yaş) bilateral izokinetik diz fleksiyon ve ekstansiyon kuvvet asimetrisini belirlemek için yaptıkları çalışmada, tüm açısal hızlarda (60, $120,180,240,300^{\circ} . \mathrm{s}^{-1}$ ) diz fleksörlerinde (\%11.0) ekstansörlere (\% 6.5) göre daha fazla kuvvet defisitleri olduğunu belirtmişlerdir. $\mathrm{Bu}$ sonuçlarla karşılaştırıldığında ipsilateral kuvvet asimetri değerleri ile bu çalışmada elde edilen kontralateral kuvvet asimetri değerlerinin yakınlık gösterdiği söylenebilir. Bununla birlikte, en fazla asimetri değerleri en yüksek açısal hızlarda $\left(300^{\circ} . \mathrm{s}^{-1}\right)$ gözlenirken (35); düşük, orta ve yüksek açısal hızlarda alt ekstremiteler arası kontralateral kuvvet asimetrisinin cinsiyetler arası farklılı bulunamayan bu çalışma ile benzerlik göstermemektedir. Tablo-1'de görülebileceği üzere, fleksiyon ve ekstansiyon simetri açı değerlerinde açısal hıza bağlı bir artış veya düşüş olmaması, simetri açı değerlerinin açısal hızlara göre de benzer olduğunu göstermektedir.

Antrenmansız genç erkeklerde düşük ve yüksek açısal hızlarda bilateral defisit görülmemesine rağmen (36), her iki bacağın lineer koşu dışında neredeyse hiçbir zaman eşit oranlarda kullanılmadığı futbol gibi daha asimetrik türdeki sporlarda (37) alt ekstremiteler arası kontralateral asimetri değerleri \%10'dan fazladır (38). Bu sonuçlar göz önüne alındığında, kontralateral asimetrinin yapilan sporun doğasına göre farklılık gösterebileceği söylenebilir. $\mathrm{Bu}$ çalışmaya katılan bireylerin belli bir spor dalına özgü spor geçmişlerinin bulunmaması nedeniyle kontralateral asimetri değerlerinde farklılık görülmediği söylenebilir. Literatürde farklı sonuçların bulunması araştırma tasarımlarındaki çeşitlilik (katılımcı grupların yaşları, antrenman düzeyleri, cinsiyet vb.) olabilir.

Trzaskoma ve ark.nın (39) çalışmasında bilateral ve ünilateral aktif sıçrama testinde elde edilen bilateral defisit sonuçlarının kadın ve erkekler arasında istatistiksel olarak anlamlı derecede farklılık göstermemesi, bu çalışmanın sonuçlarıyla benzerlik göstermektedir. Sıçrama farklı süreçlerden etkilenebilen çoklu eklem içeren bir hareket olmasına rağmen sonuçları bakımından bu çalışma ile benzeşmektedir.

$\mathrm{Bu}$ çalışma, konsantrik izokinetik diz kuvvet asimetrisiyle sınırlıdır. Farklı yaş grupları ve spor dallarında alt ve üst ekstremitelerin ünilateral, bilateral veya ipsilateral kuvvet asimetrisinin sportif performansa ve rehabilitasyon süreçlerine etkilerini inceleyen çalışmalar tasarlanabilir. 
Sonuç olarak, fiziksel olarak aktif ancak üst düzeyde antrenmanlı olmayan sağlıklı bireylerde yüksek, orta ve düşük açısal hızlarda kontralateral izokinetik konsantrik diz kuvveti açı değerleri simetrisinin cinsiyetler arasında farklılık göstermediği saptanmıştır.

Etik Kurul: Karar tarihi: 29.01.2019, sayı: 25403353-050.99-E.12498, Evrak doğrulama adresi: https://ebysnetm.ogu.edu.tr/Home/ Dogrulama/ac9e967e-0ed7-46e7-b0add6c689dc04bc

\section{KAYNAKLAR}

1. Impellizzeri FM, Rampinini E, Maffiuletti N, et al. A vertical jump force test for assessing bilateral strength asymmetry in athletes. Med Sci Sports Exerc. 2007;39(11):2044-50.

2. Zifchock RA, Davis I, Higginson J, et al. The symmetry angle: a novel, robust method for quantifying asymmetry. Gait Posture. 2008;27(4):622-7.

3. Bishop C, Read P, Chavda S, et al. Asymmetries of the lower limb: The calculation conundrum in strength training and conditioning. Strength Cond J. 2016;38(6):27-32.

4. Türksoylu A, İşlegen Ç. Kuvvet ve sportif yaralanmaların önlenmesindeki önemi. Turk J Sports Med. 2013;48(1):9-16.

5. McCall A, Carling C, Nedelec M, et al. Risk factors, testing and preventative strategies for non-contact injuries in professional football: current perceptions and practices of 44 teams from various premier leagues. Br J Sports Med. bjsports-2014;48(18):1352-7.

6. Brito J, Figueiredo P, Fernandes L, et al. Isokinetic strength effects of FIFA's "The 11+" injury prevention training programme. Isokinet Exerc Sci. 2010;18(4):211-5

7. Hewit JK, Cronin JB, Hume PA. Asymmetry in multidirectional jumping tasks. Phys Ther Sport. 2012;13(4):238-42.

8. Kim D, Hong J. Hamstring to quadriceps strength ratio and noncontact leg injuries: A prospective study during one season. Isokinet Exerc Sci. 2011;19(1):1-6.

9. Kuruganti U, Seaman K. The bilateral leg strength deficit is present in old, young and adolescent females during isokinetic knee extension and flexion. Eur J Appl Physiol. 2006;97(3):322-6.

10. Ayral D. İlk yardım ve sportif rehabilitasyon ilkeleri. Turk J Sports Med. 2013;48(2):57-68.

11. Alsancak S. Patolojik yürüyüş. Ankara Sağlık Hizmetleri Dergisi. 2016;15(1):25-32.

12. Karakuş D, Erdoğdu DD, Delialioğlu SÜ, et al. Patellofemoral ağrı sendromu: Fonksiyonel kapasite üzerine izokinetik egzersiz programının ev egzersiz programı ile karşılaștırma sonuçları. Turk J Phys Med Rehab. 2014;60(1);63-7.

13. Croisier JL, Forthomme B, Namurois $\mathrm{MH}$, et al. Hamstring muscle strain recurrence and strength performance disorders. Am J Sports Med. 2002;30(2):199-203.

14. Newton RU, Gerber A, Nimphius S, et al. Determination of functional strength imbalance of the lower extremities. J Strength Cond Res. 2006;20(4):971-7.

15. Keeley DW, Plummer HA, Oliver GD. Predicting asymmetrical lower extremity strength deficits in college-aged men and women using common horizontal and vertical power field tests: a possible screening mechanism. J Strength Cond Res. 2011;25(6):1632-7.

16. Robinson RO, Herzog W, Nigg BM. Use of force platform variables to quantify the effects of chiropractic manipulation on gait symmetry. J Manipulative Physiol Ther. 1987;10(4):172-6.

17. Exell TA, Irwin G, Gittoes MJ, et al. Implications of intralimb variability on asymmetry analyses. J Sports Sci. 2012;30(4):403-9.

18. Lephart SM, Ferris CM, Riemann BL, et al. Gender differences in strength and lower extremity kinematics during landing. Clin Orthop Relat Res. 2002;401:162-9.

19. Heyward VH, Johannes-Ellis SM, Romer JF. Gender differences in strength. Res Q Exerc Sport. 1986;57(2): 154-9.

20. Daneshjoo A, Rahnama N, Mokhtar AH, et al. Bilateral and unilateral asymmetries of isokinetic strength and flexibility in male young professional soccer players. $J$ Hum Kinet. 2013;36(1):45-53.

21. Ferber R, Davis IM, Williams DS 3rd. Gender differences in lower extremity mechanics during running. Clin Biomech (Bristol, Avon). 2003;18(4): 350-7.

22. Young WB, James R, Montgomery I. Is muscle power related to running speed with changes of direction? $J$ Sports Med Phys Fitness. 2002;42(3): 282-8.

23. Bailey C, Sato K, Alexander R, et al. Isometric force production symmetry and jumping performance in collegiate athletes. J Trainol. 2013;2(1):1-5.

24. Hannah R, Folland JP, Smith SL, et al. Explosive hamstrings-to-quadriceps force ratio of males versus females. Eur J Appl Physiol. 2015;115(4): 837-47.

25. Holm I, Vøllestad N. Significant effect of gender on hamstring-to-quadriceps strength ratio and static balance in prepubescent children from 7 to 12 years of age. Am J Sports Med. 2008:36(10): 2007-13.

26. Jaiyesimi AO, Jegede JA. Hamstring and quadriceps strength ratio: effect of age and gender. J Nigeria Soc Physiother. 2005;15(2):54-8.

27. Hewett TE., Myer GD, Zazulak BT. Hamstrings to quadriceps peak torque ratios diverge between sexes with increasing isokinetic angular velocity. J Sci Med Sports. 2008;11(5):452-9.

28. Aoki H, Demura S. Characteristics and lateral dominance of hand grip and elbow flexion powers in 
young male adults. J Physiol Anthropol. 2008;27(4), 201-6.

29. Chan KM, Maffulli N, Korkia P, et al. Principles and Practice of Isokinetics in Sports Medicine and Rehabilitation. Hong Kong: Williams \& Wilkins; 1996. p. 117-22.

30. Brown LE, Whiteburst M. Load range. In: Brown LE, Ed. Isokinetics in Human Performance. Champaign IL: Human Kinetics; 2000. p. 114.

31. Erdfelder E, Faul F, Buchner A. GPOWER: A general power analysis program. Behav Res Methods. 1996;28(1):1-11.

32. Faul F, Erdfelder E, Lang AG, et al. G* Power 3: a flexible statistical power analysis program for the social, behavioral, and biomedical sciences. Behav Res Methods. 2007;39(2):175-91.

33. Pancholi B, Dunne MCM, Armstrong R. Sample size estimation and statistical power analyses. Optometry Today. 2010;16(7):10-8.
34. Veligekas P, Bogdanis GC. Bilateral deficit in vertical jumping in pre-pubertal boys and girls. JPES. 2013;13(1):120-6.

35. Maly T, Zahálka F, Malá L. Unilateral and ipsilateral strength asymmetries in elite youth soccer players with respect to muscle group and limb dominance. Int $J$ Morphol. 2016;34(4):1339-44.

36. Maly T, Zahálka F, Malá L, et al. The bilateral strength and power asymmetries in untrained boys. Open Med J (Wars). 2015;10(1):224-32.

37. Iga J, George $\mathrm{K}$, Lees $\mathrm{A}$, et al. Cross-sectional investigation of indices of isokinetic leg strength in youth soccer players and untrained individuals. Scand J Med Sci Sports. 2009;19(5):714-9.

38. Rahnama N, Lees A, Bambaecichi E. Comparison of muscle strength and flexibility between the preferred and non-preferred leg in English soccer players. Ergonomics. 2005;48(11-14):1568-75.

39. Trzaskoma Z, Ilnicka L, Wiszomirska I, et al. Laterality versus jumping performance in men and women. Acta Bioeng Biomech. 2015;17(1):103-10. 